\title{
Pesquisa
}

\section{SÍNDROME DE BURNOUT EM ESTUDANTES UNIVERSITÁRIOS}

\author{
Gislene Farias de Oliveira (1) \\ Maria Vanessa Tavares Grangeiro (2) \\ Julianne de Oliveira Paes Barreto (3)
}

\begin{abstract}
Resumo
Este estudo objetivou demonstrar a Síndrome de Burnout como um problema social, formado por uma complexa rede de fatores intervenientes e que, assim como aos profissionais, tende a afetar os estudantes de áreas da saúde. Por tratar-se de uma área emergente em termos de estudos científicos, as referências ainda são precárias e os estudos restritos a algumas especificidades. Dessa forma, a temática demanda mais estudos que proporcionem novos rumos aos estudos e iniciativas em termos de iniciativas preventivas com vistas à melhoria da qualidade de vida e de formação profissional em saúde.
\end{abstract}

Palavras-chave: Saúde ; Estudantes; Síndrome de Burnout.

\section{Introdução}

O avanço da tecnologia e dos estudos em saúde coletiva, tem revelado enfermidades consideradas emergentes, dentre elas o Estresse, a depressão e a Síndrome de Burnout (Comisión de las Comunidades Europeas, 2007).

Esta última, tem sido considerada um problema social em diversos países. (Maslach, Schaufeli e Leiter, 2001; Harrison, 1999).

A Síndrome de burnout foi descrita por primeira vez em 1974 nos Estados Unidos por Herbert Freudenberger, a partir de estudos sobre a perda de motivação e comprometimento, acompanhados de sintomatologias psíquicas e físicas, como a perda de energia e a presença de fadiga, manifestados por voluntários de uma instituição para tratamento de drogados (Freudenberger \& Richelson, 1980; Schaufelli \& Buunk, 1996). Não obstante, quase 
paralelamente, Christina Maslach também utilizou a expressão burnout como resultado da uma pesquisa sobre a influência da carga emocional do trabalho no comportamento de profissionais de saúde, assistentes sociais e advogados (Maslach \& Jackson, 1981, 1985).

Apesar da evidência de que existirem elementos psíquicos que podem ser integrados e explicados sob a denominação de burnout, predomina um número considerável de definições e teorias a respeito, demandando-se uma aproximação ao tema de modo a melhor compreendê-lo. Neste sentido, a continuação se procura tratá-lo conceitualmente, reunindo as principais teorias e medidas que têm sido freqüientemente utilizados para explicar esta síndrome em si e ou seus antecedentes e conseqüentes.

Burnout, expressão inglesa que significa "queimar-se" ou "consumir-se pelo fogo", foi utilizada pela fácil semelhança metafórica com o estado de exaustão emocional, o "estar consumido", fenômeno vivenciado mais freqüente e intensamente por algumas categorias profissionais (Maslach \& Schaufeli, 1993; Schaufelli \& Buunk, 1996). De acordo com alguns estudiosos da temática, o burnout surge inicialmente como um problema social (Schaufeli \& Enzmann, 1998), sendo descrito na literatura como uma síndrome psicológica, resultado de uma tensão emocional freqüente, vivenciada por profissionais que dependem de relacionar-se freqüentemente com pessoas que necessitam de algum tipo de assistência. É apresentado como um construto multidimensional, formado por: exaustão emocional, despersonalização (ou cinismo) e diminuição da realização pessoal (Maslach, 1993; Maslach \& Jackson, 1986).

Segundo Maslach (1993; Maslach \& cols., 2001), a exaustão emocional se caracteriza por sentimentos de fadiga e falta de energia para manter-se em sua atividade laboral. Neste caso, o indivíduo se sente exaurido emocionalmente. A despersonalização diz respeito a atitudes negativas de aspereza e de distanciamento em relação às pessoas do ambiente de trabalho, normalmente aquelas a quem se pretende beneficiar. Finalmente, a dimensão de realização pessoal é caracterizada por uma auto-avaliação negativa do indivíduo, normalmente relacionada com sentimentos de incompetência e de desempenho insatisfatório no trabalho.

Benbow (1998) salienta que a SB costuma estar acompanhada, além destas três dimensões, de uma série de sintomas como sentimentos de indefesa e desesperança, carência de entusiasmo no trabalho e na vida em geral, desilusão, autoconceito negativo, atitudes negativas frente ao trabalho e aos companheiros, dentre outros.

Alguns autores, a exemplo de Schaufeli e Buunk (1996), consideram que as manifestações do burnout devem ser classificadas em diferentes dimensões, como as descritas a seguir: 
- Dimensão afetiva. Com relação ao aspecto afetivo, são relatados o humor depressivo, o sentimento de desesperança, a baixa auto-estima, a falta de significado, a ansiedade e os sentimentos de impotência no trabalho, a intolerância à frustração, hostilidade, hipersensibilidade e desconfiança. O burnout diminui a motivação para o trabalho, levando o indivíduo a uma percepção distorcida e pessimista da vida.

- Dimensão cognitiva. Nesta dimensão são relatadas a dificuldade de concentração e memorização, a dificuldade para tomar decisões e a presença de sintomas sensório-motores, como os tiques nervosos, a agitação e a incapacidade para relaxar (Kahill, 1988).

- Dimensão física. Esta dimensão abarca os sintomas psicossomáticos, tais como citam Freudenberger (1974) e Arches (1991): resfriados freqüentes, problemas gastrointestinais, dores de cabeça, fadiga, insônia, sensação de exaustão, tremores e falta de ar.

- Dimensão comportamental. Neste âmbito, alguns autores relatam a intensificação no uso de drogas, conduta de evitação, irritação fácil, frustração, hiperatividade e dificuldade para controlar as emoções (Arches, 1991; Freudenberger, 1974). Não obstante, outros também apontam o absenteísmo, a baixa produtividade, os atrasos no trabalho, os acidentes, os roubos, a negligência e a intenção de abandonar o emprego (Schaufeli \& Buunk, 1996).

- Dimensão social. Nesta dimensão as manifestações sociais mais freqüentes são os problemas com os clientes, colegas, superiores e subordinados, por conta de um comportamento de evitação dos contatos sociais (Maslach, 1978). A diminuição do envolvimento no trabalho tende a interferir na vida familiar, aumentando os conflitos interpessoais; as pessoas com burnout correm o risco de se isolarem.

- Dimensão atitudinal. São relatados nesta dimensão a desumanização, a insensibilidade, a indiferença e o cinismo no trato com os clientes (Maslach, 1978; Maslach \& Jackson, 1986). Também a perda de entusiasmo, interesse e idealismo, o que pode levar ao absenteísmo e abandono do emprego.

Embora os sintomas do burnout sejam comumente confundidos com aqueles da depressão, Schaufeli e Buunk (2003) afirmam que as sintomatologias destas patologias apresentam variações, não sendo conceitos intercambiáveis e redundantes. Alguns estudos demonstram que burnout e depressão emergem por diferentes fatores (Bekker \& cols., 2000; Leiter \& Durup, 1994; McKnigt, 1993; Schaufeli \& Buunk, 2003). Segundo BenevidesPereira (2002), a pessoa que vivencia o burnout identifica sua atividade como desencadeante do processo e, apresenta uma sintomatologia com prevalência de sentimentos de 
desapontamento e tristeza. Por outro lado, na depressão há prevalência de sentimentos de derrota e letargia para a tomada de atitude.

O interesse científico despertado pelo Burnout tem ampliadoseu campo de estudo, abrangendo inclusive não somente trabalhadores e profissionais, como também estudantes (Schaufeli, Martinez, Pinto, Salanova e Bakker, 2002, Carlotto et al., 2006).

No caso dos estudantes universitários, a sua atividade deve ser levada em conta como uma atividade pré-profissional. Neste caso, o conceito de Burnout em estudantes também se constitui de três dimensões: Exaustão Emocional, caracterizada pelo sentimento de estar exausto em virtude das exigências do estudo; Descrença, entendida como o desenvolvimento de uma atitude de cinismo e distanciamento com relação ao estudo; e Ineficácia Profissional, caracterizada pela percepção de estarem sendo incompetentes como estudantes (Carlotto et al 2006).

O Burnout em profissionais da área da saúde já é uma questão já consolidada em diferentes estudos (Oliveira, 2008; Maslach, 1982; Maslach, Schaufeli e Leiter, 2001; Rodríguez-Marín, 1995). Dessa forma, é possível pensar no Burnout em estudantes da área da saúde, também como uma questão relevante. Esses estudantes são submetidos a uma série de estressores típicos de quem atua diretamente com pessoas, podendo também assimilar conflitos e dificuldades dos pacientes. Autores como Cushway (1992) observaram que o início de Burnout pode se dar durante a fase acadêmica, no período de preparação para o trabalho.

Segundo Carlotto et al (2006), os cursos que abrangem a área da saúde geralmente possuem uma prática de estágio através da qual os estudantes percebem as implicações e limitações de seu conhecimento, quando da aplicação dos mesmos. Isto é, nas primeiras intervenções junto aos clientes, costumam surgir dúvidas, medos e ansiedades relacionadas à prática terapêutica.

Em geral o conhecimento adquirido na universidade, são um tanto superficiais, nem sempre abrangendo toda a sorte de especificidades próprias da atividade prática do dia-a-dia. Dessa forma, muitos conhecimentos não se aplicam à realidade, uma vez que esta se reveste de uma singularidade própria humana.

Nogueira-Martins, 2002 observaram que os maiores receios dos estudantes das áreas de saúde são os que dizem respeito a cometer algum erro, prejudicar o cliente e não serem reconhecidos por parte dos colegas e professores.

Já Balogun, Helgemore, Pellegrino e Hoerberlein (1995) referem que o ambiente de competição encontrado entre alunos, professores e outros profissionais no âmbito da atividade 
educacional é que são geradores de conflitos entre os mesmos, conflitos estes que podem levar ao estresse e à exaustão emocional. Nogueira - Martins (2002) observaram ainda que a falta de tempo para o lazer, família, amigos e necessidades pessoais, como também preocupações quanto ao futuro profissional e as dívidas acadêmicas também são fatores de estresse e exaustão emocional.

Um dos agravantes do Burnout é que, se este se inicia no período de formação, pode também prosseguir durante a vida profissional, comprometendo qualitativamente a eficácia do trabalho desenvolvido. Assim, detectar precocemente níveis sintomáticos significativos pode constituir um indicador de possíveis dificuldades, tanto em nível de êxito escolar como profissional, possibilitando intervenções preventivas, como sugerem Martinez, Pinto, Salanova e Silva (2002).

Neste sentido, a prevenção de Burnout se mostra importante, desde o início da formação do profissional da saúde, uma vez que este estará em contato direto com o paciente, dispensando-lhes cuidado e atenção e assim, exposto a uma enorme variedade de estressores. Trata-se de um grupo particularmente afetado pelo estresse ocupacional e, conseqüentemente, pelo Burnout (Mendes e Nunes, 1999; Gil-Monte, 2002).

Em estudo realizado em porto Alegre, com 514 estudantes da área de saúde, Carlotto et al (2006) observaram que, com relação a Síndrome de Burnout, a dimensão Exaustão Emocional apresentou média de 2,88, indicando a existência de desgaste emocional pelos alunos "algumas vezes ao mês". Na Descrença, a média obtida foi de 1,40, indicando sentimento de pouca confiança no ensino "uma vez ao mês ou menos". Com relação ao sentimento de Eficácia Profissional, o a média obtida pelo grupo foi de 4, 90, demonstrando que o aluno sente-se competente como estudante praticamente "todos os dias".

Um outro ponto observado neste mesmo estudo foi que, quanto menor a idade dos sujeitos, maiores a Exaustão Emocional e a Descrença com o ensino, e menor o sentimento de Eficácia Profissional. Também ficou evidenciada a relação entre a Exaustão Emocional, o semestre cursado, o número de disciplinas e o ano de ingresso no curso. Quanto mais avançado o semestre, quanto maior o número de disciplinas cursadas e quanto mais recente o ingresso no curso, menor é o sentimento de Desgaste Emocional. A descrença também se associou negativamente ao ano de início de curso, evidenciando que quanto mais recente o ingresso, menor o sentimento de Descrença.

A conclusão dos autores foi que, embora os resultados obtidos com relação aos índices de Burnout não tenham apontado a presença da síndrome de Burnout, de acordo com os critérios de indicação referidos por Schaufeli et al. (2002). Segundo os autores, altos 
escores em Exaustão e Descrença e baixos escores em Eficácia Profissional são indicativos de Burnout. Neste estudo verifico-se a escala de pontuação de 0 a 6 , um índice médio/baixo em Exaustão Emocional, baixo em Descrença e alto em Eficácia Profissional. Sendo a Exaustão Emocional a primeira dimensão a surgir, esta, evidenciando um índice médio mais elevado, poderia ser um possível indicativo de Burnout no futuro, de acordo com os critérios estabelecidos para caracterizar a Síndrome e já citados anteriormente.

Dessa forma, pode-se pensar na possibilidade de estudantes de áreas de saúde, apresentarem risco de desenvolver Burnout, estando a Síndrome, pelo menos neste estudo, provavelmente sendo contida pelo alto índice de Eficácia Profissional.

Segundo Cherniss (1980) os jovens apresentam maiores níveis de Síndrome de Burnout devido ao seu entendimento irrealístico sobre o que podem ou não fazer, sendo, portanto, freqüentes as frustrações profissionais. Já segundo Maslach (1982), os maiores índices de Síndrome de Burnout em jovens se justifica pelo fato dos mesmos terem de aprender a lidar com as demandas do trabalho.

Concluímos pois que, a Síndrome de Burnout é formado por uma complexa rede de fatores intervenientes e que, assim como aos profissionais, tende a afetar os estudantes de áreas da saúde.

Por tratar-se de uma área emergente em termos de estudos científicos, as referências ainda são precárias e os estudos restritos a algumas especificidades.Trata-se de uma temática que demanda mais estudos, principalmente com delineamentos longitudinais, que dariam novos rumos aos estudos e iniciativas em termos de prevenção.

Os resultados já encontrados pelos diversos profissionais aqui abordados já sinalizam a importância de intervenções, que propiciem aos alunos, estratégias de apoio necessárias para a sua formação, com vistas à melhoria da sua qualidade de vida e de formação profissional.

\section{Referências}

Arches, J. (1991). Social structure, burnout and job satisfaction. Social Work, 36, 202-206.

Balogun, J., Helgemoe, S., Pelegrini, E. \& Hoeberlein, T. (1995). Test-retest reability of a psychometric instrument designed to measure physical therapy student's Burnout. Perceptual and Motor Skill, 81, 667-672. 
Benevides-Pereira, A. M. T. (2002). Burnout: O processo de adoecer pelo trabalho. Em A. M. T. Benevides-Pereira (Org.), Burnout: Quando o trabalho ameaça o bem-estar do trabalhador (pp.21-92). São Paulo: Casa do Psicólogo.

Carlotto, M.S.; Nakamura, A P.; Câmara, S.G. (2006). Síndrome de Burnout em Estudantes universitarios da área de Saúde. Rev. Psico. V.37, n.1, pp.57-62. 2006.

Comisión de las Comunidades Europeas. (2007). Como adaptarse a los cambios en la sociedade y en el mundo del trabajo: Una nueva estrategia comunitaria de salud y seguridad (2002-2006). Recuperado em 26 de Janeiro de 2008 de http://europe.osha.eu.int/systems/strategies/future/com2002_es.pdf.

Freudenberger, H. J. (1974). Staff burn-out. Journal of Social Issues, 30, 159-165.

Freudenberger, H. \& Richelson, G. (1980). Burnout: The high cost of high achievement. New York: Bantan Books.

Gil-Monte, P. R. (2002). Influencia del género sobre el proceso de desarrollo del síndrome de quemarse por el trabajo (Burnout) en profesionales de enfermería. Psicologia em Estudo, 7, 1, 3-10.

Harrison, B. J. (1999). Are you to burn out? Fund Raising Management, 30, 3, 25-28.

Martínez, I. M. M., Pinto, A. M., \& Silva, A. L. (2000). Burnout em estudantes do ensino superior. Revista Portuguesa de Psicologia, 35, 151-167.

Martínez, I. M. M., Pinto, A. M., Salanova, M. \& Silva, A. L. (2002). Burnout en estudiantes universitarios de España y Portugal [On-line]. Simpósio "Burnout en contextos educativos", Universitat Jaume I, Castellón. http://fsmorente.filos.ucm.es/ publicaciones/Iberpsicologia/congreso/programa.htm (Acessado em 12/03/2003).

Maslach, C., Schaufeli, W. B. \& Leiter, M. P. (2001). Job Burnout. Annual Review Psychology, 52, 397-422.

Maslach, C. (1978). The client role in staff burnout. Journal of Social Issues, 34, 11-24.

Maslach, C. (1993). Burnout: A multidimensionalidade perspective. Em W. B. Shaufeli, C. Maslach \& T. Marek (Orgs.), Professional burnout: Recet developments in theory and research (pp. 19-32). Washington, DC: Taylor \& Francis.

Maslach, C. \& Jackson, S. E. (1981). The measurement of experienced burnout. Journal of Occupational Behavior, 2, 99-113.

Maslach, C. \& Jackson, S. E. (1985). The role of sex and family variables in burnout. Sex Roles, 12, 837- 851. 
Maslach, C. \& Jackson, S. (1986). Maslach Burnout Inventory Manual. Palo Alto, CA: Consulting Psichologist Press.

Maslach, C. \& Schaufelli, W. B. (1993). Historical and conceptual development of burnout. Em W. B. Schaufelli, C. Maslach \& T. Marek (Orgs.), Professional burnout: Recent developments in theory and research (pp. 1-18). Washington, DC: Taylor \& Francis.

Maslach, C., Schaufeli, W. B. \& Leiter, M. P. (2001). Job burnout. Annual Review of Psychology, 52, 397-422.

Nogueira-Martins, M. C. F. (2002). Humanização das relações assistenciais: A formação do profissional de saúde. São Paulo: Casa do Psicólogo.

Oliveira, G. F. (2008). Trabalho e Bem-estar subjetivo: compreendendo a situação laboral dos médicos. Tese de Doutorado em psicologia Social. Universidade Federal da ParaíbaUFPB. João Peessoa-PB.

Schaufelli, W. B. \& Buunk, B. P. (1996). Professional burnout. Em M. J. Schabracq, J. M., Winnubst \& C. L. Cooper (Orgs.), Handbook of Work and Health Psychology (pp. 311346). London: Wiley.

Schaufelli, W. B. \& Buunk, B. P. (2003). Burnout: an overview of 25 years of research an theorizing. Em M. J. Schabracq, J. A. M. Winnusbst \& C. L. Cooper (Eds.), The handbook of work and health psychology (pp. 383-425). New York: John Wiley \& Sons.

Schaufeli, W. B., Martinez, I. M., Pinto, A. M., Salanova, M. \& Bakker, A. B. (2002). Burnout and engagement in university students. A Cross National Study, 33, 5, 464-481.

\section{Sobre os autores:}

(1) Gislene Farias de Oliveira é Psicóloga, Doutora em Psicologia Social e Professora da Universidade Federal do Ceará. E-mail: gislenefo@ hotmail.com

(2) Maria Vanessa Tavares Grangeiro é Médica pela Universidade Federal do Ceará.

(3) Julyanne de Oliveira Paes Barreto é Graduada pela Faculdade Ítalo-Brasileira - SP, Coordenadora do curso de extensão de Formação de Comissãrios de Vôo pela FACISA - Faculdade de Ciências Aplicadas de Campina Grande - PB. E-mail: July_paes2@ hotmail.com 